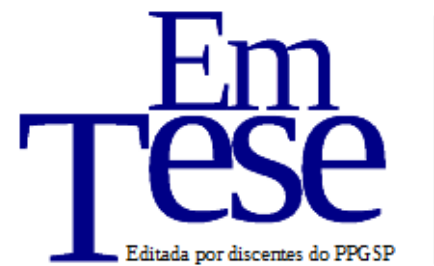

\title{
Pesquisa social interpretativa alemã: os métodos de entrevista narrativa biográfica e de reconstrução biográfica de caso ${ }^{1}$
}

\author{
Lucas Cé Sangalli ${ }^{2}$ \\ Débora Rinaldi ${ }^{3}$
}

\begin{abstract}
Resumo: A pesquisa social interpretativa alemã desenvolve e aplica métodos qualitativos de pesquisa mais intensamente desde a década de 1970. O principal objetivo do artigo é apresentar e discutir os métodos de entrevista narrativa biográfica e de reconstrução biográfica de caso sistematizados pela socióloga alemã Gabriele Rosenthal em seu livro Pesquisa Social Interpretativa (2014). Estes métodos aplicam os princípios de uma pesquisa social interpretativa, os quais têm suscitado interesse em pesquisadores brasileiros nos últimos anos. Na primeira parte do artigo, apresentamos os pressupostos teóricos e metodológicos de uma pesquisa social interpretativa. Posteriormente, explicamos e discutimos as etapas de uma reconstrução biográfica de caso com base em dados gerados em uma entrevista narrativa biográfica. Por fim, apresentamos um estudo brasileiro e outro alemão para demonstrar como estes métodos permitem reconstruir a gênese dos fenômenos sociais e explicar sua manifestação no presente, avançando em relação a métodos que se restringem a uma análise sincrônica e descritiva dos fenômenos. Isto contribui para o desenvolvimento de uma sociologia histórica do conhecimento e para o estabelecimento de uma tipologia sociogenética dos fenômenos sociais.
\end{abstract}

Palavras-chave: Pesquisa social interpretativa; Entrevista narrativa biográfica; Reconstrução biográfica de caso; Pesquisa biográfica.

\section{German social interpretive research: the methods of biographical narrative interview and biographical} case reconstruction

\begin{abstract}
German interpretive social research has improved and used qualitative research methods more commonly since the 1970s. The main aim of this article is to introduce and discuss the biographical narrative interview and the biographical case reconstruction methods systematized by German sociologist Gabriele Rosenthal in her book Interpretative Sozialforschung (Interpretive Social Research). These methods apply principles of an interpretive social research, which have been increasingly used by Brazilian scholars in the last years. In the first part of the article, we present theoretical and methodological assumptions of an interpretive social research. Then, we describe and discuss the phases of a biographical case reconstruction based on data generated during a biographical narrative interview. At last, we present a Brazilian and a German study to demonstrate how the methods of biographical narrative interview and biographical case reconstruction allow for the reconstruction of the genesis of social phenomena and the explanation of their current manifestation. Thus, they advance in relation to methods that focus on a synchronic and descriptive analysis of phenomena and contribute for the development of a historical sociology of knowledge and the establishment of a socio-genetic typology of social phenomena.
\end{abstract}

Keywords: Interpretive social research; Biographical narrative interview; Biographical case reconstruction; Biographical research.

\footnotetext{
1 (c) EY EY Esta obra está licenciada com uma Licença Creative Commons Atribuição 4.0 Internacional.

${ }^{2}$ Lucas Cé Sangalli é pesquisador no Centro de Métodos em Ciências Sociais da Universidade de Göttingen, Alemanha, e aluno do Doutorado em Ciências Sociais da mesma universidade. E-mail: lucas.sangalli@ sowi.unigoettingen.de.

${ }^{3}$ Débora Rinaldi é aluna do Doutorado em Ciências Sociais da Pontifícia Universidade Católica do Rio Grande do Sul (PUCRS). E-mail: dkleinrinaldi@gmail.com.
} 


\section{Introdução}

A variedade de métodos orientados por um paradigma de uma pesquisa social interpretativa (interpretative Sozialforschung) de língua alemã, que tem Max Weber (18641920) como um de seus pioneiros, permanece pouco conhecida e aplicada no Brasil. Dentre outros métodos de pesquisa qualitativa, aqueles alinhados a um paradigma social interpretativo se distinguem dos demais porque buscam a generalização teórica no caso particular em detrimento de generalizações com base na frequência estatística com que determinado fenômeno social se repete (ROSENTHAL, 2014). Atualmente, há uma série de teóricos, pesquisadores e escolas sociológicas empenhadas em dar continuidade à pesquisa social interpretativa, que se tem consolidado, principalmente na sociologia de língua alemã, pelo uso conjunto de refinamento teórico e trabalho empírico. Mais do que testar teorias, os métodos que apresentaremos contribuem para refutá-las pelo desenvolvimento de consciência empírica ${ }^{4}$. Isso é possível devido ao nível de abertura, sistematização e controle proporcionado pelos métodos na geração ${ }^{5}$ e na análise dos dados. Estes são alguns dos motivos pelos quais esse modo de fazer e refletir sobre a pesquisa na sociologia tem se legitimado e suscitado interesse em pesquisadores brasileiros.

A pesquisa social interpretativa (interpretative Sozialforschung) é um paradigma de pesquisa que tem seu principal foco nas interpretações feitas pelos sujeitos sobre suas experiências no mundo social. Ela passa a se difundir mais fortemente na Alemanha a partir da década de 1970, tendo como fundamentação teórica importantes clássicos da sociologia compreensiva (verstehende Soziologie) alemã do início do século XX e dialoga com

\footnotetext{
${ }^{4}$ Consciência empírica caracteriza o uso refletido de determinado método (abdutivo) ou instrumento de pesquisa, por este corresponder aos princípios metodológicos da pesquisa. Em outras palavras, o uso consciente de métodos que combinam refinamento teórico e trabalho de campo. O procedimento abdutivo, que será exposto mais adiante, esclarece a relação entre experiência em campo e teoria, ou seja, como esta corrobora para a compreensão do campo, e como este fornece dados que ampliam, refutam ou sugerem novas teorias. Em procedimento abdutivos, há uma reflexão sobre o ato de gerar hipóteses (e não somente sobre sua testagem) (ROSENTHAL, 2014). Além disso, as hipóteses não estão condicionadas à intuição do pesquisador, mas a suas interações no mundo social (FANN, 1970).

${ }^{5}$ Utilizamos o termo geração de dados para enfatizar a dimensão da construção interativa dos dados em um processo de pesquisa, especialmente com outros parceiros em situações de entrevistas. Com isso, evitamos a noção de que dados possam ser "coletados" ou "levantados" sem passar por uma construção interativa entre aqueles que vivenciam os fenômenos sociais. Optamos, com isso, por utilizar os termos biografado e biógrafo para referir os participantes de uma situação de entrevista porque acreditamos na necessidade de explicitar a situação do pesquisador nesse contexto. É relevante mencionar que a situação de entrevista se desenvolve e transforma durante a interação e está sujeita às mais variadas possibilidades de construção interativa. Aqui é importante destacar que, mesmo dados desenvolvidos em laboratórios sob circunstâncias tidas como controladas, também precisam ser interpretados pelos pesquisadores. Desta forma, concebê-los como "objetivos" revela falta de reflexão sobre o processo de investigação em questão. Os dados podem, no entanto, ser independentes da interpretação de quem os vivenciou, mas a apresentação e a interpretação dos resultados acontecem inescapavelmente em um mundo socialmente construído. Para mais, ver Berger e Luckmann (1985) e Rosenthal (2014; 2017).
} 
pesquisadores da Escola de Chicago. Embora aproxime diferentes correntes sociológicas (teoria fundamentada, hermenêutica objetiva e etnometodologia) e métodos de geração e análise de dados, todos partilham de princípios comuns, principalmente no que corresponde à representatividade empírica a partir da generalização teórica no caso concreto, à possibilidade da descoberta de hipóteses e teorias, e ao nível de abertura na pesquisa (ROSENTHAL, 2014). Rosenthal (2014) formula as seguintes possibilidades e limitações empíricas da pesquisa interpretativa em comparação a pesquisas quantitativas e outros métodos qualitativos.

Quadro 1 - Possibilidades e limitações de uma pesquisa social interpretativa.

\begin{tabular}{l}
\hline Possibilidades \\
\hline - Investigar o novo e o desconhecido, isto é, quando o pesquisador busca informações sobre um fenômeno \\
ainda pouco conhecido, principalmente no que corresponda ao seu processo de constituição; \\
\hline - Apreender o sentido subjetivamente visado, isto é, as motivações dos sujeitos na sua tomada de decisão em \\
consonância com o estoque de conhecimento socialmente compartilhado; \\
\hline - Reconstruir o sentido latente, que significa dizer que, para além da intenção da ação, existe um significado \\
objetivo da ação, não acessível ao agente; \\
\hline - Reconstruir as estruturas de ação a partir do caso particular, ou seja, reconstruir as diferentes variáveis que \\
constituem o fenômeno no caso concreto; \\
\hline - Descrever o ambiente e a ação social de forma detalhada e precisa; \\
\hline - Desenvolver teorias e hipóteses a partir do campo, fundadas empiricamente; \\
\hline - Verificar essas hipóteses e teorias produzidas a partir do campo na sequência do texto. \\
\hline - Conclusões sobre dispersão e representatividade de seus resultados; \\
\hline - Generalizações numéricas e estatísticas baseadas na frequência de como os fenômenos aparecem. \\
\hline Fonte: Rosentacos
\end{tabular}

Fonte: Rosenthal (2014, p. 34).

Nesse sentido, temos como objetivo apresentar os métodos de entrevista narrativa biográfica e de reconstrução biográfica de caso $^{6}$ desenvolvidos pela socióloga alemã Gabriele Rosenthal, que sistematizou os princípios de uma pesquisa social interpretativa. Além da apresentação dos métodos, baseada no livro de Gabriele Rosenthal, Pesquisa Social Interpretativa: uma introdução (2014), faremos contribuições sobre nossa experiência no uso destes métodos. Devido ao interesse crescente de pesquisadores sociais brasileiros por

\footnotetext{
${ }^{6}$ Utilizamos a tradução do alemão para biographische Fallrekonstruktion da versão em português de Rosenthal (2014). Outra tradução possível seria reconstrução de caso biográfico, para enfatizar a dimensão biográfica do caso e não de sua reconstrução. É importante enfatizar que, na literatura acadêmica brasileira, os dois métodos apresentados no artigo também são referidos pelos termos abordagem ou método de narrativas biográficas.
} 
abordagens narrativas e biográficas, como manifestado em grupos de trabalho e discussões do $18^{\circ}$ Congresso Brasileiro de Sociologia (2017) em Brasília, e com base na baixa produção de estudos qualitativos na sociologia brasileira, escrevemos esse artigo.

O artigo está estruturado da seguinte forma: primeiramente, descrevemos os pressupostos teóricos e metodológicos de uma pesquisa social interpretativa. Em um segundo momento, apresentamos princípios teóricos da aplicação dos métodos de entrevista narrativa biográfica e de reconstrução biográfica de caso e exemplos do seu uso em estudos na Alemanha e no Brasil. Nas considerações finais, enfatizamos como a reconstrução de casos biográficos permite compreender e explicar não somente um nível sincrônico (presente) da manifestação dos fenômenos sociais, mas um nível diacrônico do processo de formação e desenvolvimento destes no passado. Com isso, é possível avançar no estudo de uma sociologia histórica do conhecimento (ROSENTHAL, 2012).

\section{Pesquisa social interpretativa: fundamentos e princípios metodológicos}

Essa seção do artigo apresenta a pesquisa social interpretativa sinalizando sua proposta dentro do campo empírico, como também seus fundamentos teóricos e princípios metodológicos, percorrendo sua origem e desenvolvimento em língua alemã e demais influências no decorrer do século XX até os dias atuais. Com isso, antes de iniciarmos a apresentação dos métodos de entrevista narrativa biográfica e de reconstrução biográfica de caso, será possível ter uma ideia dos fundamentos e princípios que regem uma pesquisa social interpretativa e os métodos aqui apresentados.

A pesquisa social interpretativa é um paradigma de pesquisa qualitativa, que se distingue de pesquisas quantitativas por ter seu foco na interpretação das experiências dos sujeitos no mundo social e nos processos de constituição de suas interpretações. Logo, compreender e explicar os fenômenos sociais são as finalidades destes métodos, assim como já defendia Max Weber na sua sociologia compreensiva (FREUND, 2003). Mais do que resultados de processos, os métodos reconstrutivos de uma pesquisa social interpretativa permitem reconstruir a formação dos fenômenos, buscando a generalização teórica no caso particular. Devido à possibilidade da descoberta do novo e do desconhecido, estes métodos podem ser combinados com métodos quantitativos ou qualitativos, como etnografias e discussões em grupo.

No que tange à pesquisa qualitativa em geral, existem diferenças importantes entre os métodos de geração dos dados e de sua análise, principalmente no que corresponde ao nível 
de abertura, sistematização e controle proposto. Em uma pesquisa social interpretativa, embora opere-se com diferentes abordagens, defende-se a maior abertura possível na geração e na análise dos dados com o intuito de assegurar o princípio da objetividade ${ }^{7}$ (ROSENTHAL, 2014).

Um dos principais fatores explicativos para o desenvolvimento da pesquisa social interpretativa na sociologia alemã foi o intercâmbio de pesquisadores entre a Alemanha e os Estados Unidos, principalmente no século XX. De um lado, temos, na Alemanha, Max Weber e seu conceito de ação social, e Georg Simmel (1858-1918) e sua noção de sociedade, ambos dando protagonismo aos indivíduos e à ação social em uma época na qual a sociologia europeia era dominada pelo funcionalismo de Auguste Comte (1798-1857) e Émile Durkheim (1858-1917). Tanto Weber como Simmel já eram conhecidos na academia americana e alemã. De outro lado, na Universidade de Chicago, havia o pragmatismo de Charles Sanders Peirce (1839-1914), John Dewey (1859-1952), William James (1842-1910) e Georg Herbert Mead (1863-1931). Muitos desses pensadores norte-americanos foram para a Alemanha complementar seus estudos, como Mead e Albion Small (1854-1926). Small foi aluno de Simmel em Berlim e fundou o primeiro departamento de sociologia da Universidade de Chicago (Ibidem).

Com a perseguição de intelectuais europeus pelos nazistas, muitos foram obrigados a deixar a Alemanha e a Áustria à época da Segunda Guerra Mundial, migrando para países como França e Estados Unidos (Ibidem). Este foi o caso de Alfred Schütz (1899-1959), importante pensador austríaco, que lecionou na New School for Social Research em Nova York em 1943. Durante os anos de exílio até a volta dos primeiros intelectuais à Alemanha, por volta de 1950, com o fim da guerra, a sociologia alemã foi dominada principalmente por métodos quantitativos (HOPF, 1978).

Somente a partir dos anos 70, a sociologia interpretativa começou a ganhar força na Alemanha por iniciativa do Grupo de Trabalho dos Sociólogos de Bielefeld ${ }^{8}$ (ROSENTHAL,

\footnotetext{
${ }^{7}$ Procedimentos abertos de pesquisa, seja na fase de geração ou de análise dos dados, permitem compreender mais facilmente como o cientista chegou aos seus resultados, já que buscam, ao utilizar uma entrevista aberta, apreender a visão de mundo apresentada pelo biografado, diminuindo a determinação do biógrafo sobre a geração dos dados (BECKER, 1993). No processo de análise, uma postura aberta do pesquisador permite que o campo mostre os fenômenos a serem explorados, evitando que nos guiemos de forma dedutiva a partir da teoria. O controle no processo de análise e a objetividade das análises são assegurados por uma análise sequencial, na qual cada passagem da entrevista é reconstruída em detalhes. Cada uma dessas etapas, desde a geração dos dados até a de hipóteses e sua verificação no caso concreto, pode ser acompanhada e revisada por examinadores externos. Nesse sentido, procedimentos abertos dão espaço para o surgimento de evidências que permitem ao pesquisador refutar seus pré-conceitos, garantindo o princípio da objetividade.

${ }^{8}$ O Grupo de Trabalho dos Sociólogos de Bielefeld fez intercâmbios científicos com cientistas sociais e sociolinguistas dos Estados Unidos nessa época e seus trabalhos assimilaram grande parte destas discussões.
} 
2014). Aqui, destacam-se nomes como Fritz Schütze (entrevista narrativa) e Ralf Bohnsack (método documentário). Também Ulrich Oevermann começa, à época, a participar das discussões sobre pesquisa social interpretativa com seu método da hermenêutica objetiva. Tanto a sociologia compreensiva, como a pesquisa qualitativa desenvolvidas na Escola de Chicago, instituto fundado na Universidade de Chicago no início do século XX, foram importantes no processo de desenvolvimento da sociologia interpretativa alemã. ${ }^{9}$ Além da Escola de Chicago, Peter Berger (1929-2017) e Thomas Luckmann (1927-2016), com a sua obra A Construção Social da Realidade (1966), são referências importantes para o fazer sociológico em língua alemã ainda hoje, tornando-se um verdadeiro divisor de águas dentro da sociologia do conhecimento (KNOBLAUCH, 2005). Berger e Luckmann foram alunos de Alfred Schütz, pensador que desenvolveu os fundamentos teóricos mais substanciais para o desenvolvimento de uma sociologia interpretativa e de orientação fenomenológica (SANTOS, 2017).

No Brasil, alguns conceitos caros à tradição da pesquisa social interpretativa foram utilizados pelo antropólogo Gilberto Velho já na década de 80, que se preocupou com "motivações, relevâncias, projetos, dentro de uma linha fenomenológica à la Schütz" (VELHO, 2012a, p. 8) em uma tentativa de relacionar essas questões à construção de uma teoria da cultura enquanto rede de significados, nos termos de Clifford Geertz. ${ }^{10}$ Velho (2012a) propôs uma aproximação da antropologia de Louis Dumont e da sociologia de orientação fenomenológica de Alfred Schütz, sintetizada na pergunta "quem é o sujeito dos projetos?”. Para Velho (2012a), há variações na ênfase dedicada às peculiaridades, gostos e preferências dos agentes empíricos e esses traços individuais relacionam-se não apenas a uma visão de mundo (eidos), à qual a noção de biografia e sua concepção de tempo são centrais, mas também a um estilo de vida, uma organização das emoções (ethos) em que "a experiência do agente empírico sacralizada como individual é o foco de referência básica" (VELHO,

Erving Goffman, Harold Garfinkel, Harvey Sacks, John Gumperz e Anselm Strauss estiveram em Bielefeld, Gottlieben e Konstanz (Alemanha) para reuniões de trabalho revolucionárias para a sociologia interpretativa na Alemanha (KÖTTIG; VÖLTER, 2014). Nesse sentido, Schütze discutiu suas reflexões sobre análise de narrativas com Harvey Sacks, fundador da análise da conversa. Apesar da receptividade de Schütze aos desenvolvimentos feitos em língua inglesa, ele relata que "nunca foi realmente aceito dentro da análise da conversa ortodoxa" (KÖTTIG; VÖLTER, 2014, p. 214).

${ }^{9}$ Sobre a diversidade e heterogeneidade englobadas pelo termo Escola de Chicago, Velho (2008, p. 146) escreve: "[A Escola de Chicago] surgiu, originalmente, no Departamento de Sociologia e Antropologia da Universidade de Chicago, mas as pessoas que ali estudaram foram se espalhando não só pelos Estados Unidos, mas também por outros países. [...] O Departamento de Sociologia e Antropologia dividiu-se em 1929, mas houve continuidade em relação a certos modos de fazer ciência social, como a preocupação fundamental com o trabalho de campo".

${ }^{10} \mathrm{O}$ antropólogo Gilberto Velho teve seu primeiro contato com a obra de Georg Simmel ainda nos anos de sua graduação e manteve relações com pesquisadores da Escola de Chicago, que influenciaram e foram influenciados por sua obra. Para mais, ver Velho (2012b). 
2012a, p. 28). Nesse sentido, Velho já buscava compreender os indivíduos em sua interrelação com agrupamentos sociais e a forma como estes constituem e são constituídos pelas ações e projetos individuais.

Em sua única obra publicada em vida, Der Sinnhaft Aufbau der sozialen Welt. Eine Einleitung in die verstehende Soziologie (A Construção significativa do mundo social - Uma introdução à sociologia compreensiva ${ }^{11}$ ), Schütz aproximou a sociologia compreensiva de Max Weber, a partir de seu entendimento de ação social, da filosofia fenomenológica de Edmund Husserl (1859-1938). Para Schütz (2004), assim como para Weber, os sujeitos agem a partir do sentido que atribuem à sua ação. Diferentemente de Weber, Schütz aprofunda a compreensão de como o sentido se constitui para o sujeito se valendo da fenomenologia de Husserl. Segundo Schütz (Ibidem), o sentido da ação se constitui na interação social a partir de certos mecanismos e regras, como o manuseio de um estoque de conhecimento socialmente compartilhado e de um sistema de relevância, ambos instrumentalizados em processos de tipificação. Assim, surge a concepção de ação na sociologia interpretativa, a qual se torna base teórica e metodológica para os métodos instrumentalizados em seu nome. A noção de que os sujeitos agem a partir de suas interpretações da realidade, constituídas através da interação social a partir de certas regras, é o que aproxima as diferentes abordagens dentro da pesquisa social interpretativa (ROSENTHAL, 2014; KLEEMANN et al., 2009). Deste fundamento, surgem dois princípios metodológicos básicos, denominados o princípio da comunicação e o princípio da abertura (HOFFMANN-RIEM, 1980), que orientam a pesquisa social interpretativa nas fases de geração e análise dos dados.

O primeiro princípio diz respeito à ideia de que toda a interação humana está situada em um contexto comunicacional e está sujeita a possibilidades e limitações deste processo. Seja essa interação uma situação de entrevista ou o ato de comprar pão na padaria, temos que levar em consideração, como sugerido por Erving Goffman (1986), os enquadramentos sociais (frame) objetivamente pré-estabelecidos e os diferentes enquadres (framing) negociados na situação de interação. ${ }^{12}$

O princípio da abertura, por sua vez, faz alusão à ideia de que o pesquisador não vai a campo com hipóteses determinadas a priori, simplesmente para buscar respaldo empírico para pressupostos teóricos. Ao contrário, a pergunta de pesquisa é realizada de forma aberta e

\footnotetext{
${ }^{11}$ Uma versão em português da obra tem lançamento previsto para 2018. No momento, há versões apenas em alemão e inglês.

${ }^{12}$ As noções de enquadre (framing) e enquadramento (frame) fundamentam o princípio da comunicação. Segundo Goffman, os agentes definem a situação e se comportam a partir desta definição. Para mais, ver Rosenthal (2014, p. 53) e Velho (2008).
} 
é detalhada ao longo do trabalho de campo. Isso deve possibilitar a descoberta do novo, de modo que dados que surgirem durante o trabalho de campo possam ter espaço para modificar ou até mesmo substituir a pergunta de pesquisa, como sugerido na lógica circular proposta por Glaser e Strauss (1967). ${ }^{13}$ Além da pergunta de pesquisa, a entrevista deve ser conduzida da forma mais aberta possível, sem um roteiro pré-estabelecido, de acordo com a cronologia estabelecida pelo parceiro de entrevista e respeitando seu sistema de relevância.

$\mathrm{Na}$ fase de análise dos dados, encontramos outro importante procedimento do princípio de abertura, que consiste na formulação de hipóteses em cima do caso empírico e não a partir de teorias já existentes, típicas do procedimento dedutivo. Esse procedimento é conhecido na sociologia como $a b d u c ̧ a ̃ o^{14}$. O procedimento da abdução permite a formulação de hipóteses a partir do caso específico, bem como o controle, testagem e manutenção ou refutação pelo próprio processo de análise. Exemplos de métodos interpretativos que se orientam pela lógica da descoberta são a hermenêutica objetiva de Ulrich Oevermann (OEVERMANN et al., 1979) e a análise de texto e de narrativas de Fritz Schütze (1983; 2010). Em algumas modalidades de pesquisa social interpretativa, a análise dos dados é reconstrutiva, ou seja, não é realizada com hipóteses ou categorias pré-estabelecidas a partir de teorias (em uma lógica da subsunção). Além dessa reconstrução ser abdutiva, ela também é sequencial $^{15}$, pois faz jus ao sistema de relevância apreendido na situação de entrevista e transcrito no texto, permitindo explorar, pelas hipóteses abdutivas, o sistema de relevância e as possibilidades de ação do biografado.

A partir de Schütz (2004), relevância e ação pressupõem um estoque de conhecimento socialmente compartilhado. Logo, a pesquisa social interpretativa não se limita às construções subjetivas, como muitas vezes é argumentado nas discussões sobre micro e macrossociologia, pois “o geral está, por princípio, implicado no particular” (ROSENTHAL, 2014, p. 90). Esse aspecto fica mais contundente quando partimos de uma análise biográfica, pois a biografia não consiste somente no resultado de uma construção subjetiva; ela é também

\footnotetext{
${ }^{13}$ Esse tipo de investigação procura fazer, ao final da análise, generalizações teóricas fundamentadas na realidade empírica, daí o nome teoria fundamentada (grounded theory) (GLASER; STRAUSS, 1967).

${ }^{14} \mathrm{O}$ método abdutivo foi proposto por Charles Sanders Peirce e comporta as três formas do pensamento lógico: abdução, dedução e indução. Na abdução, as hipóteses são geradas a partir do caso. Na dedução, as hipóteses são geradas a partir da teoria e, na indução, as hipóteses são levadas a campo para serem testadas no caso. Para mais, ver Rosenthal (2014, p. 72).

${ }^{15} \mathrm{O}$ princípio da sequencialidade significa que a análise é feita de forma sequencial em correspondência à sucessão dos acontecimentos, respeitando a estrutura do texto, sem que este seja desmembrado (ROSENTHAL, 2014). Essa é uma das diferenças em relação à análise de conteúdo, que reorganiza o texto por subsunção a categorias analíticas, desconsiderando seu contexto de surgimento e uso (ROSENTHAL, 2014).
} 
dual, isto é, produto de um processo individual e coletivo ao mesmo tempo (ROSENTHAL, 2014; RADENBACH; ROSENTHAL, 2012). ${ }^{16}$

\section{Os métodos de entrevista narrativa biográfica e de reconstrução biográfica de caso}

Essa seção do artigo apresenta e discute os procedimentos de geração e análise de dados como sugeridos pela socióloga alemã Gabriele Rosenthal nos métodos de entrevista narrativa biográfica (SCHÜTZE, 1983; 2010) e de reconstrução biográfica de caso (ROSENTHAL, 2014). Além das etapas do método, exemplificadas a partir do material gerado em um estudo sobre migração feito por um dos autores (CÉ SANGALLI, 2015; 2018), também gostaríamos de contribuir com reflexões decorrentes da nossa experiência com o método.

É essencial ressaltar dois momentos distintos desse procedimento metodológico. O primeiro diz respeito à geração dos dados em uma entrevista narrativa biográfica. O segundo, faz referência à análise desses dados, dividida em quatro etapas principais por Rosenthal (2014): a) análise sequencial dos dados biográficos, b) análise sequencial de texto e do campo temático, c) reconstrução da vida vivenciada, d) contraste entre vida vivenciada e vida narrada e construção tipológica.

\subsection{Geração dos dados: a entrevista narrativa biográfica}

O procedimento de entrevista narrativa traduz o princípio da abertura de uma pesquisa social interpretativa (HOFFMANN-RIEM, 1980). A entrevista inicia com uma pergunta ampla ao parceiro de entrevista, de modo a evitar um enquadramento dos temas a serem abordados. Isto é, em uma pesquisa com migrantes a respeito da gênese da decisão de deixar o país natal, ao invés de perguntar "Por que você saiu de seu país?" ou "O que te motivou a deixar seu país?", é feita uma pergunta aberta, como "Eu gostaria que você me contasse sobre sua história de vida e a de seus familiares". Trata-se, deste modo, de uma pesquisa biográfica no sentido mais amplo do conceito, não estando restrita apenas ao tema de pesquisa ou à reconstrução da história de vida de um indivíduo. Não nos interessam apenas os fatos

\footnotetext{
16 "A pesquisa biográfica trabalha sistematicamente como uma teoria interacionista da socialização que busca apreender a relação constitutiva entre as definições construídas pelo próprio indivíduo e as que partem do outro, ou, dito de forma geral, a relação constitutiva entre geral e particular e os efeitos dessa relação. [...] Uma pesquisa biográfica que pretende compreender a relação constitutiva entre indivíduo e sociedade deve sempre buscar identificar as regras do discurso que regem a ação e também suas variações no contexto dos relatos biográficos" (ROSENTHAL, 2014, p. 222-223).
} 
diretamente relacionados ao tema de pesquisa e à história de um indivíduo, mas demais experiências biográficas em sua dimensão social (ROSENTHAL, 2014). Narrativas reproduzem, mais do que outras formas de relato, as estruturas da ação, o que as aproxima da forma como determinado fenômeno social foi vivenciado pelo indivíduo (SCHÜTZE, 2010). Nesse sentido, reconstruir os níveis de análise da história de vida vivenciada e da história de vida narrada (ROSENTHAL, 2017) vai além de outros métodos, como o de história de vida ou de história oral, que nem sempre estabelecem uma diferença entre os níveis de análise e que se focam, em muitos casos, ou em eventos históricos "maiores" que o indivíduo ou na história sobre a vida de um indivíduo. Por outro lado, “em análises biográficas, não se trata apenas de considerar as definições construídas pelo indivíduo sobre sua biografia, mas também de analisar interpretações feitas por outras pessoas" (ROSENTHAL, 2014, p. 221). Investigamos as atribuições de sentido feitas por outros indivíduos em relação ao biografado em determinados contextos e o modo como elas estão inter-relacionadas com suas ações e construções biográficas (ROSENTHAL, 2014). ${ }^{17}$ Nesse sentido, é uma sociologia das

\footnotetext{
${ }^{17}$ Aqui é importante esclarecer as diferentes abordagens biográficas e a confusão gerada pelo uso não refletido do conceito de biografia e de história de vida. Há uma diferença paradigmática entre a pesquisa biográfica francesa (muito difundida em países da América do Sul) e a alemã. O método de história de vida (récit de vie) de Daniel Bertaux é o mais proeminente na sociologia francesa. Bertaux (2010) chama sua perspectiva de etnosociológica, já que combina uma concepção etnográfica com outra sociológica. A principal diferença em relação ao paradigma interpretativo difundido em língua alemã é o fato de o paradigma francês se orientar essencialmente pelas "realidades práticas e materiais, políticas e sociais" em detrimento de realidades discursivas e simbólicas (BERTAUX, 2010, p. 11, tradução dos autores). O objetivo da abordagem difundida por Bertaux não é o de adquirir conhecimento sobre os esquemas de representação, os sistemas de valores e crenças de uma pessoa ou partilhados pelos membros de um grupo social, mas, ao contrário, seu objetivo é estudar uma parte ou um segmento particular da realidade sócio-histórica - um objeto social - e descobrir como ele funciona e se transforma (BERTAUX, 2010). Bertaux acredita que histórias de vida "revelam os efeitos constritivos das relações sócio-estruturais que constituem o objeto da pesquisa sociológica estruturalista" (BERTAUX; KOHLI, 1984, p. 226, tradução dos autores). Em síntese, para Bertaux, o foco deve estar nas "práticas" e não nas percepções ou sentimentos das pessoas, o que o afasta significativamente do paradigma interpretativo e de orientação fenomenológica apresentado neste artigo. Em sentido similar, situa-se a concepção "disposicionalistacontextualista" de Bernard Lahire (2005; 2017), que se distancia de uma "visão homogeneizante do indivíduo na sociedade" e do foco de pesquisa em "sua visão de mundo, o seu relacionamento com o mundo ou $a$ fórmula geradora das suas práticas (o habitus)" (LAHIRE, 2005, p. 25). Lahire (2005; 2017) identifica uma diversidade de limitações na obra de Pierre Bourdieu, mas reproduz sua leitura limitada da fenomenologia alemã (nega principalmente a noção de ser-no-mundo de Martin Heidegger). Propõe que, "se queremos compreender o que 'anima' os indivíduos, o que os conduz a agir como agem, a dedicarem-se a um domínio ao invés de outro, etc., é necessário apreender os desejos e as preocupações predominantes que eles foram levados a forjar durante sua história. Para esse fim, a biografia social, como uma objetificação de tempos, frameworks, modalidades e efeitos de socialização diferentes através da jornada individual, é uma ferramenta indispensável para os pesquisadores" (LAHIRE, 2017, p. 11, tradução dos autores). A grande diferença da perspectiva de Lahire em relação à apresentada neste artigo é o fato de ele compreender o mundo de forma externa ao indivíduo (em oposição a um mundo subjetivo de orientação fenomenológica) e, com isso, objetificar o mundo externo e cair em um dualismo entre constrangimentos internos (disposicionais) e externos (contextuais), ressoando ecos da tradição francesa de Émile Durkheim e Pierre Bourdieu. Não é, portanto, uma diferença em relação à compreensão das biografias em sua dimensão social nem do seu uso como dado sociológico, mas sobre como proceder no processo de geração de dados (Lahire se orienta de forma indutiva e não se preocupa com os esquemas interpretativos dos sujeitos) e de reconstrução de casos biográficos, ignorando princípios centrais de uma pesquisa social interpretativa apresentados no artigo. Isso parece se dar devido à falta de diálogo entre Lahire e pesquisadores da abordagem
} 
figurações sociais e dos processos nos termos de constituição mútua entre indivíduo e sociedade sugeridos por Norbert Elias (1994). Usamos a abordagem biográfica como forma de acesso a essas vivências individuais - e sempre sociais - para superar divisões micro, meso e macrossociológicas. ${ }^{18}$

Quando perguntado sobre sua vida e a de sua família, o migrante eventualmente abordará o tema da migração (um fenômeno social) quando e se achar necessário, o que trará informações sobre como a decisão de deixar seu país ganhou forma ao longo de sua vida. Evita-se, assim, o foco exacerbado em uma única motivação ou em um único deslocamento, o que geralmente acontece quando fazemos perguntas argumentativas (e que ensejam respostas argumentativas). De outro modo, uma resposta narrativa contém uma estrutura sintática mais descritiva do processo de migração como vivenciado pelo biografado em diversos momentos de sua vida, fornecendo conhecimento mais próximo à forma como o fenômeno foi vivenciado em diferentes contextos e regiões.

Após o parceiro de entrevista encerrar o primeiro momento da entrevista, no qual o biógrafo intervém apenas utilizando mecanismos paralinguísticos que ensejam a narrativa (como movimentos afirmativos com a cabeça, contato visual, etc.), o biógrafo inicia uma segunda fase da entrevista, na qual poderá fazer perguntas narrativas (ou seja, que respeitem uma lógica sobre como algo aconteceu em detrimento do por quê ou quando algo ocorreu) valendo-se de temas apresentados pelo parceiro de entrevista no momento inicial (por exemplo, utilizando termos usados por ele para fazer as perguntas). Essa fase corresponde ao aprofundamento de temas e eventos biográficos trazidos pelo parceiro de entrevista na fase inicial. Para tanto, o biógrafo utiliza linguagem e termos apresentados pelo parceiro de entrevista de forma a ensejar narrativas que contenham em sua estrutura lembranças sobre como certos eventos biográficos foram vivenciados. Em um terceiro momento, é possível fazer perguntas externas aos temas abordados inicialmente, como sobre sua constelação

biográfica de língua alemã, já que muitos pontos que ele reivindica (assim como dos autores que utiliza para fundamentar sua perspectiva, como M. Weber, S. Freud, N. Elias, C. S. Peirce, H. Becker, E. Goffman, P. Berger, T. Luckmann) já terem sido superados ou assimilados pela abordagem biográfica em língua alemã. O descompasso entre Lahire e a abordagem alemã fica mais evidente quando ele identifica um "medo ritualístico" em relação ao desenvolvimento de um método biográfico, que ele considera "mais imaginado ou preconcebido do que realmente praticado pelos pesquisadores em ciências sociais" (LAHIRE, 2017, p. 12, tradução dos autores). Isto denota sua baixa familiaridade com os métodos apresentados neste artigo, aplicados e discutidos na sociologia alemã desde a década de 1970. A determinação de Lahire (2017) para pôr fim à incompreensão de Bourdieu e sua ilusão biográfica indica esforços contemporâneos para difundir também na sociologia francesa uma abordagem biográfica. Para mais sobre as diferentes abordagens da pesquisa biográfica, ver o dossiê da Revista Civitas (SANTOS; VÖLTER; WELLER, 2014). Sobre diferenças e similaridades entre história oral e a abordagem aqui apresentada, ver Rosenthal e Worm (2018). Para outra recepção francesa da obra de Martin Heidegger (e da fenomenologia e da hermenêutica), ver Zarader (2012).

${ }^{18}$ Para mais a respeito das considerações metodológicas sobre biografias, discursos e figurações a partir de uma perspectiva social construtivista e da sociologia das figurações, ver Bogner e Rosenthal (2017). 
familiar para estabelecer um genograma ${ }^{19}$ ou sobre um tema não abordado no contexto interativo até então.

O pesquisador gera os dados em campo, analisa-os e o resultado dessas análises determina a amostragem teórica, isto é, quais entrevistas serão realizadas até chegar em uma saturação teórica, ou seja, quando casos começarem a se repetir. Como podemos perceber, a geração e a análise dos dados ocorrem sempre de forma paralela. Para cada uma das entrevistas, é escrito um memorando com a descrição e as impressões do pesquisador a respeito da interação anterior e posterior à entrevista com o parceiro de entrevista. As experiências em campo e o contexto das entrevistas devem ser detalhadamente registrados. Estes dados não devem ser vistos como interferências externas que atrapalham a investigação, mas como constituintes da intersubjetividade subjacente à interação entre parceiros em uma situação de entrevista. A honestidade do pesquisador acerca de suas impressões em campo contribui para situar posições e para o uso posterior destes dados na reconstrução do caso.

De modo geral, entrevistas narrativas são longas e exaustivas não somente para o pesquisador, mas também para o parceiro de entrevista, que tematiza, em muitos casos, questões sensíveis sobre seu passado. Caso a dificuldade apresentada pelo parceiro de entrevista para falar de determinado tema seja grande, recomenda-se o retorno em momento posterior para outra entrevista. O valor terapêutico de entrevistas narrativas já foi apresentado em estudos anteriores (ROSENTHAL, 2003), principalmente quando os biografados integram agrupamentos sociais pouco escutados ou que não despertam grande interesse midiático. Nesse sentido, a experiência de falar sobre si pode ser inédita. Por isso, recomenda-se cautela na condução da rememoração, uma vez que os assuntos podem ser sensíveis. Ao finalizar esse tipo de entrevista, Rosenthal (2014) sugere que o biógrafo pergunte a respeito de memórias felizes vivenciadas pelo biografado como forma de encerrar o encontro em um tom positivo. Com base em nossa experiência, perguntamos se o parceiro de entrevista tem alguma questão para ser feita ao biógrafo, dando oportunidade de construção de outra situação de entrevista.

Também recomendamos a condução de mais de uma entrevista com o mesmo parceiro em espaços de tempo distintos, como forma de avaliar alterações temáticas e de formato na narrativa sobre si em diferentes momentos, mesmo que nos mesmos contextos. Trabalhos prévios (SANTOS GONÇALVES; CÉ SANGALLI, 2018) indicam mudanças temáticas significativas em um espaço de tempo de cerca de um ano entre uma entrevista e outra. Nesse sentido, a possibilidade de fazer entrevistas follow-up (de acompanhamento) dá acesso à

\footnotetext{
${ }^{19} \mathrm{O}$ genograma é um instrumento utilizado para informar o pesquisador, dentre outras coisas, sobre a constelação familiar do biografado. Para mais, ver Rosenthal (2014).
} 
forma como o processo de reinterpretação sobre as experiências passadas se desenvolve, permitindo que hipóteses levantadas anteriormente sejam reforçadas ou descartadas nessa lógica aberta e circular de geração de dados no campo e na formação de teorias. As próximas seções do capítulo apresentam detalhes do procedimento de análise dos dados gerados em situações de entrevistas narrativas biográficas de acordo com as sugestões de Rosenthal (2014).

2.2. Análise de dados: a reconstrução biográfica de caso e a tipologia

De acordo com os pressupostos de Gabriele Rosenthal (2014), a análise de dados biográficos é feita com base na transcrição de entrevistas biográficas e nos memorandos redigidos para cada uma das entrevistas. A transcrição é feita de acordo com códigos específicos, que buscam transcrever interrupções, entonação e mudança de falante baseados, em grande medida, em sugestões da análise da conversa (ROSENTHAL, 2014). Apesar de não detalhados neste artigo, o procedimento de reconstrução biográfica de caso também pode levar em consideração dados gerados em observações participante, gravações audiovisuais e etnografias (Ibidem).

\section{a) Análise sequencial de dados biográficos}

A primeira etapa da análise corresponde à análise sequencial dos dados biográficos do biografado, que consiste no estabelecimento de hipóteses abdutivas para a vida vivenciada, chegando à uma hipótese estrutural para a vida vivenciada (a hipótese final que sistematiza aquelas que resistiram à prova empírica no caso). As hipóteses são formuladas com base em dados objetivos da biografia dispostos cronologicamente, os quais são analisados de forma independente da interpretação que o biografado faz deles; também é desconsiderado o conhecimento do pesquisador sobre as fases seguintes da vida do biografado. Isso cumpre com o objetivo de reconstruir "o contexto de um acontecimento com o qual o entrevistado foi confrontado" (ROSENTHAL, 2014, p. 227). Esse tipo de análise é importante porque informa o pesquisador a respeito da estrutura da ação do biografado. Ou seja, através da análise sequencial dos dados biográficos e da geração de hipóteses abdutivas, é possível adquirir conhecimento a respeito dos cursos de ação que se apresentaram perante o indivíduo em determinado momento de sua vida e que foram escolhidos em detrimento de outras alternativas. 
Exemplos de dados objetivos são a quantidade de irmãos do biografado, sua situação de nascimento, histórico de doenças, formação profissional, dentre outros, que são dispostos em uma cronologia dos eventos biográficos da história de vida e que são gerados por meio da entrevista narrativa ou por outras fontes. Dados referentes ao contexto histórico e social são inseridos nessa cronologia, como mudanças econômicas, desastres ambientais (grandes secas ou terremotos, por exemplo), ou mudanças legislativas que possam influenciar a vida do biografado. Nesse sentido, esta etapa fornece informação a respeito do contexto da tomada de decisão do indivíduo à época em que as ações foram efetivadas.

Seguindo o procedimento abdutivo, a partir destas hipóteses primárias, são estabelecidas hipóteses secundárias e follow-up sobre possíveis caminhos que o biografado poderia ter seguido e que demonstram como as ações podem responder a outras lógicas que não àquela das decisões efetivadas. Com essa análise, procura-se um padrão de ação que se manifesta recorrentemente nas opções representadas nos dados seguintes da cronologia e que pode informar o investigador a respeito de sua estrutura de ação.

Rosenthal (2014) sugere que, nesta etapa, seja feito um genograma, que sistematiza informações do biografado e possibilita avaliar a existência de fatores determinantes em gerações anteriores e que podem ter influenciado sua socialização, como, por exemplo, a transmissão do pertencimento religioso por parte da família materna. A análise do genograma segue o mesmo procedimento lógico pelo qual as hipóteses são levantadas com base nos dados empíricos e depois são contrastadas com a sequência dos dados biográficos da entrevista.

A seguir, apresentamos uma versão sintetizada da análise sequencial dos dados biográficos de um migrante vindo do Haiti que vivia no Brasil à época da entrevista. Apresentamos somente dois dados biográficos como forma de ilustrar esta etapa. Para isso, utilizamos um dado relacionado ao seu nascimento e outro relacionado ao contexto econômico, político e social de sua infância, para ilustrar o modo como o contexto de determinada região pode ser integrado à análise do curso de ação de indivíduos.

Quadro 2 - Dados biográficos e hipóteses para vida vivenciada.

\begin{tabular}{|c|}
\hline DADOS BIOGRÁFICOS E HIPÓTESES PARA VIDA VIVENCIADA \\
\hline $\begin{array}{l}\text { 1. VIII/1988 - Nasce em região rural no interior do Haiti (próximo da capital). Família vive vida de } \\
\text { subsistência. }\end{array}$ \\
\hline $\begin{array}{l}\text { 1.1. A família compensa dificuldades econômicas criando forte vínculo com a comunidade. (hipótese principal/abdução) } \\
\text { 1.1.1. Os pais do biografado sentem-se amparados pela comunidade da região. } \underline{\text { (hipótese secundária/dedução) }} \\
\text { 1.1.1.1. Ele sente orgulho de suas origens. (follow up/dedução) } \\
\text { 1.1.1.1.1. Ele vai crescer em um ambiente com forte sentimento comunitário e isso se refletirá em escolhas relacionadas à vontade de } \\
\text { retribuir e prestar auxílio. (follow up/dedução) }\end{array}$ \\
\hline
\end{tabular}




\subsection{A família não compensa dificuldades econômicas criando vínculo com a comunidade .}

1.2.1. Ele e sua família saem da região em busca de condições de vida mais favoráveis.

1.2.2. O biografado e sua família permanecem na região, mas nutrem um sentimento de desamparo e descaso, que se reflete no trato violento dos pais com ele e seus irmãos.

1.2.2.1. Ele cresce com dificuldades para estabelecer relações interpessoais.

1.2.2. Ele encontra no abandono da família uma alternativa ao cotidiano violento.

1.2.2.3. Ele faz escolhas que indicam a reprodução da violência familiar.

1.2.3. Os pais não se sentem amparados pela comunidade na região.

1.2.3.1. Ele cresce em um ambiente voltado mais para sua família do que para a comunidade e isso se refletirá em suas escolhas futuras, que poderão estar relacionadas a uma vontade de se distanciar da região.

1.2.3.1.1. Ele tem vergonha de sua região.

\subsection{A gravidez foi planejada.}

1.3.1. Ele é bem recebido pelos pais e sente-se cuidado e amparado.

1.3.1.1. Ele cresce ciente do amor que sua família tem por ele, o que se reflete em escolhas arriscadas por saber que conta com o amparo familiar.

1.3.1.2. Ele cresce ciente do amor que sua família tem por ele, o que resulta em um sentimento extremado de proteção, que dificulta seu afastamento do núcleo familiar.

\subsection{A gravidez não foi planejada.}

1.4.1. Ele não é bem recebido por sua família.

1.4.1.1. Ele cresce temeroso a respeito do amor que sua família tem por ele, o que se reflete em baixa autoconfiança

1.4.1.1.1. Ele faz escolhas fortemente relacionadas à aprovação dos outros.

1.4.1.2. Ele faz escolhas que o distanciam, cada vez mais, de sua família.

1.4.2. Ele é bem recebido pelos pais e sente-se cuidado e amparado.

1.4.2.1. Ele cresce ciente do amor que sua família tem por ele, o que se reflete em escolhas arriscadas por saber que conta com o amparo familiar

1.4.2.2. Ele cresce ciente do amor que sua família tem por ele, o que resulta em um sentimento extremado de proteção, que dificulta o afastamento dele de seu núcleo familiar.

1.5. A família conta com o auxílio financeiro de familiares que vivem no exterior.

1.5.1. Ele cresce em um ambiente no qual pode ser estabelecida uma associação entre "país estrangeiro" e melhores condições de vida.

1.5.1.1. Ele pode optar por viver fora do Haiti.

1.5.2. Ele cresce em um ambiente no qual pode ser estabelecida uma associação entre sua família e a vida que vivenciam no interior com a falta de recursos e a pobreza.

1.5.2.1. Ele desenvolve um sentimento de vergonha em relação a sua família.

1.5.1.1. Ele se afasta de sua família e da sua região.

2. XII/1990 - Jean Bertrand Aristide é eleito presidente. O Haiti recebe ajuda econômica dos Estados Unidos.

2.1. A eleição presidencial é percebida pela população como um avanço das instituições democráticas do país.

2.1.1. A geração que cresce no Haiti à época é influenciada por valores liberais e democráticos dos Estados Unidos.

2.1.1.1. O biografado faz escolhas relacionadas à influência norte-americana, como o senso de empreendedorismo e self-made man ou, até mesmo, vai para os Estados Unidos.

2.1.1.2. Ele cresce com um sentimento de admiração pelos Estados Unidos, mas de insatisfação em relação ao Haiti.

2.2. A eleição presidencial é percebida pela população como ingerência externa.

2.2.1. A geração que cresce no Haiti à época nutre um sentimento de oposição aos Estados Unidos, fortalecendo um sentimento nacionalista.

2.2.1.1. Ele faz escolhas relacionadas ao futuro de sua nação, o Haiti, dado o sentimento de pertencimento ensejado.

2.2.1.2. Ele cresce em um ambiente onde há a radicalização de ações em relação à influência estrangeira, como o aumento das guerrilhas de oposição ao regime do presidente Aristide.

2.2.1.2.1. Ele eventualmente envolve-se em manifestações de oposição ao regime.

2.3. O auxílio econômico é revertido em desenvolvimento social das áreas rurais.

2.3.1. A região onde vive a família do biografado é beneficiada e tem acesso à saúde e educação.

2.3.1.1. Ele pode-se dedicar integralmente aos estudos.

2.3.2. A região onde vive a família dele tem acesso à moradia de qualidade.

2.3.2.1. Ele desenvolve um sentimento de aconchego e conforto na região, de modo a planejar permanecer nela no futuro.

2.3.2.2. Ele cresce em um ambiente amplo, permitindo que a família viva de modo confortável.

2.3.2.2.1. Há poucos conflitos por espaço na casa dele, o que resulta em um ambiente de convivência pacífica.

2.4. O auxílio econômico não é revertido em desenvolvimento social das áreas rurais.

2.4.1. A região onde vive a família dele não é beneficiada por programas sociais.

2.4.1.1. O sentimento dele e dos habitantes da região é de descaso do governo para com eles.

2.4.1.1.1. Cria-se um sentimento de ceticismo em relação à influência norte-americana e às instituições democráticas.

2.4.2. A situação econômica da família é agravada.

2.4.2.1. Ele e sua família deixam a região em direção a um lugar com melhores condições de vida.

Fonte: Autores (2018). 
O quadro evidencia o procedimento trifásico da abdução de hipóteses explicativas a partir dos dados empíricos. Deste modo, a hipótese principal (1.1. A família compensa dificuldades econômicas criando forte vínculo com a comunidade) é sugerida abdutivamente com base nos dados biográficos gerados durante a entrevista (o dado biográfico não depende da interpretação do biografado; neste caso, é sua data de nascimento em uma região rural do Haiti no final da década de 1980). A partir do fenômeno empírico, sugere-se uma hipótese geral explicativa, a qual deve ser verificável e estar relacionada a fatos passíveis de observação (ROSENTHAL, 2014).

A partir daí, por dedução, surgem as hipóteses secundárias (1.1.1. Os pais do biografado sentem-se amparados pela comunidade da região) e de acompanhamento ou follow-up (1.1.1.1. e 1.1.1.1.1.). As hipóteses secundárias e de acompanhamento não partem do dado empírico, mas do conteúdo da hipótese primária (abdutiva). Nesse sentido, elas são as decorrências lógicas das afirmações contidas na hipótese primária.

Por fim, por inferência indutiva, as hipóteses são testadas em relação aos dados empíricos. O conteúdo das hipóteses anteriores é contrastado com o trecho seguinte do texto transcrito, de forma a comprovar a plausibilidade das hipóteses levantadas na fase anterior, refutá-las ou modificá-las (Ibidem). No caso apresentado, suponhamos que, em uma sequência seguinte da entrevista, emergisse um dado que colocasse um conflito entre a comunidade da região e a família do biografado. Esse teste indutivo refutaria a hipótese principal 1.1. e todas as hipóteses dela decorrentes. No entanto, a hipótese principal 1.2. ganharia maior poder explicativo e continuaria sendo submetida aos dados subsequentes presentes no texto.

A lógica de discutir o surgimento de hipóteses em grupos de análise é fundamental, uma vez que coloca os dados construídos em campo em contato com pesquisadores que não estiveram envolvidos na situação da entrevista e que desconhecem trechos subsequentes do texto. Além disso, permite ampliar o horizonte de possibilidades de ação dos indivíduos com as sugestões feita por outros pesquisadores.

Ao final desta etapa, o pesquisador fica somente com as hipóteses passíveis de serem levantadas e comprovadas com base nos dados empíricos. Com isso, evitamos uma lógica da subsunção a categorias, pela qual o pesquisador usa os dados para confirmar hipóteses projetadas por ele sobre o material empírico. Este procedimento indutivo é comum na maior parte de outras formas de pesquisa interpretativa, como na análise de conteúdo, nas quais o material empírico é usado para comprovar categorias sugeridas pelo próprio pesquisador. Este 
tipo de análise não passa por uma lógica sequencial e reconstrutiva porque utiliza excertos selecionados pelo analista, que usa métodos classificatórios (procurando, por exemplo, trechos textuais onde o parceiro de entrevista fala sobre uma categoria que o investigador determinou ex ante). Nesse sentido, compreendemos que uma pesquisa que vai a campo com hipóteses explicativas para um fenômeno e busca dados para validar sua lógica está, em grande medida, fechada ao descobrimento de novas explicações, em plena oposição ao princípio da abertura apresentado anteriormente. Da mesma maneira, a importância de sempre colocarmos as contra-hipóteses para as hipóteses que serão sugeridas na pesquisa (como 1.3. A gravidez foi planejada e 1.4. A gravidez não foi planejada). Com isso, evitamos simplesmente respaldar preconcepções que o pesquisador (sempre) tem. Após a prova nos dados empíricos, a contra-hipótese ou a hipótese inicial se mostrará mais plausível. ${ }^{20}$

Em resumo, a manutenção do princípio da abertura no processo de pesquisa e o uso de procedimentos abdutivos podem ser descritos da seguinte maneira. Com um interesse de pesquisa amplo em mente, o pesquisador vai a campo sem hipóteses definidas para descobrir quem poderá ser entrevistado. Nesse primeiro momento em campo, o pesquisador gera seus dados com pessoas de diversos contextos - aqui é importante não se restringir a um único local de acesso aos entrevistados. No caso de um estudo sobre migração, isso significa não focar em apenas uma instituição em busca de contatos ou depender de somente um grupo restrito de pessoas para ter acesso ao campo. Também é importante gerar entrevistas com pessoas de diferentes agrupamentos, os quais devem ser estabelecidos ao longo do trabalho de campo, quando o pesquisador é capaz de observar quais são os agrupamentos estabelecidos em determinadas figurações e quais os outsiders, quais os responsáveis pelos discursos predominantes e quais estão sujeitos a essa distribuição de poder. Após as observações, é possível determinar quem será entrevistado, bem como quem será possível entrevistar e, em outro momento, sobre o que as pessoas estão autorizadas ou não a falar (ROSENTHAL, 2016a).

Com algumas entrevistas geradas e transcritas, o pesquisador pode iniciar o processo de análise. Com base nos dados que aparecem nas entrevistas, é possível propor as primeiras hipóteses explicativas para o fenômeno em questão. Como em procedimentos arqueológicos onde evidências surgem do trabalho em campo na forma de moedas antigas, objetos

\footnotetext{
${ }^{20} \mathrm{Em}$ contraste a uma abordagem psicanalítica, por exemplo, na abordagem biográfica, o pesquisador se esforça no sentido de evitar o uso de categorias pré-determinadas (seja pela literatura, seja pelos discursos, como o da patologização de certos fenômenos) e, em oposição a isso, busca "reconstruir o significado dos fenômenos individuais em seu contexto de surgimento" (ROSENTHAL, 2014, p. 221). Um diagnóstico psicanalítico tenderia mais a um entendimento seletivo dos fenômenos de acordo com critérios teóricos, aos quais subsume conceitos já construídos (Ibidem).
} 
cotidianos, dentre outros -, no método de reconstrução biográfica de caso, as evidências surgem na transcrição da entrevista e nas observações. As evidências sugerem explicações variadas (e, sempre que possível, aparecem também suas contra-hipóteses) para o fenômeno. A validade dessas hipóteses explicativas é posta a prova (indutivamente) em relação às outras evidências que emergem na análise sequencial dos trechos textuais seguintes (ou através de novas observações). $\mathrm{Na}$ arqueologia, inicialmente são encontrados indícios da existência de uma população até então não registrada em determinada região (ou mencionada somente em histórias orais), como artefatos cotidianos, ruínas de construções, moedas antigas. Lentamente, as pistas emergem do trabalho de campo e uma explicação convincente e historicamente plausível pode ser proposta. É necessário ter em mente que há sempre a possibilidade de outros trabalhos, feitos por outras gerações (ou pelo mesmo pesquisador em um momento posterior), mudarem a figura se novas evidências forem esclarecidas. A validade das interpretações deve resistir ao teste do tempo, mas estar sempre aberta à mudança. ${ }^{21}$

b) Análise textual e de campo temático (reconstrução da vida narrada - erzählte Lebensgeschichte)

Esta etapa compreende a estrutura da apresentação biográfica do parceiro de entrevista e a reconstrução da sua história narrada. Nesta etapa, a entrevista transcrita é segmentada de acordo com o tema dos trechos, dispostos na ordem do relato em unidades de análise. Isso objetiva fornecer uma visão geral (Gestalt) da entrevista, como forma de o pesquisador visualizar quando determinados temas foram abordados (ou omitidos) e qual tipo textual foi utilizado pelo biografado para falar sobre algo.

De acordo com Rosenthal (2014), esta etapa trabalha elementos da análise de campo temático de Aron Gurwitsch com uma abordagem sequencial e abdutiva em conjunto com o método de Fritz Schütze $(1983 ; 2010)$ para análise de texto. O principal objetivo da etapa é investigar, a partir do presente, regras atreladas à gênese da narrativa biográfica no momento da entrevista (ROSENTHAL, 2014). Ou seja, ao contrário da etapa anterior e da reconstrução da história de vida vivenciada, nesta não interessa o modo como o biografado vivenciou o evento biográfico, mas as razões pelas quais ele, de modo consciente ou latente, narra os

\footnotetext{
${ }^{21}$ Para mais sobre o processo de reinterpretação envolvido na descoberta de artefatos durante escavações arqueológicas, ver os relatos sobre a expedição organizada pelo Royal Ontario Museum em meados da década de 1970 no "Palácio de Yazdigird", construído no auge da Rota da Seda no oeste do Irã (https://www.rom.on.ca/en/blog/rom-alfred-wirth-gallery-of-the-middle-east-stronghold-of-an-iranian-warlordon-the-silk-road).
} 
eventos de determinada forma e de acordo com certas estruturas (ROSENTHAL, 2017). Isto permite identificar quais temas não são abordados pelo parceiro de entrevista e como ele estrutura o relato de suas vivências de acordo com campos temáticos específicos ou evita outras formas expressivas (ROSENTHAL, 2014; 2017).

Com base na segmentação e na definição dos temas, são formuladas hipóteses abdutivas para o significado de cada sequência do texto (ROSENTHAL, 2014). Esta etapa procura "apreender a relação constitutiva entre a escolha tanto do tipo de texto quanto do tema e do conteúdo do relato e o processo interacional entre entrevistado e pesquisador" (ROSENTHAL, 2014, p. 238), isto é, determinar se o parceiro de entrevista está usando seu sistema de relevância ou está sujeito àquele do biógrafo.

Quadro 3 - Segmentação, campo temático e hipóteses para vida narrada.

\begin{tabular}{|c|c|c|c|c|}
\hline \multicolumn{5}{|c|}{ SEGMENTAÇÃO, CAMPO TEMÁTICO E HIPÓTESES PARA VIDA NARRADA } \\
\hline Sequência & $\begin{array}{l}\text { Página/linha } \\
\mathrm{N}^{\mathrm{o}} \text { de linhas }\end{array}$ & Falante & $\begin{array}{l}\text { Tipo } \\
\text { textual }\end{array}$ & Conteúdo e hipóteses para interesse de apresentação \\
\hline 2 & $\begin{array}{c}1 / 8-12 \\
(5)\end{array}$ & $\begin{array}{c}\text { Nome } \\
1^{22}\end{array}$ & Relatório & $\begin{array}{l}\text { Nome, país de origem, membros da família, pergunta se deve contar a história } \\
\text { da família ou falar sobre morar um período de tempo em algum lugar. } \\
\text { 2.1. Apresenta sua história sinteticamente porque está acostumado a falar } \\
\text { sobre si, de modo que o faz de maneira concisa. } \\
\text { 2.2. Apresenta sua história sinteticamente porque não quer dar muitos detalhes. } \\
\text { Não gosta de falar de si. } \\
\text { 2.3. Apresenta sua história sinteticamente porque não entendeu a pergunta } \\
\text { inicial }\end{array}$ \\
\hline 3 & $\begin{array}{c}1 / 13 \\
(1)\end{array}$ & $\begin{array}{c}\text { Nome } \\
2\end{array}$ & Explicação & $\begin{array}{l}\text { Explica que não há restrição de tempo (em francês). } \\
\text { 3.1. O parceiro de entrevista falará em francês. } \\
\text { 3.2. O parceiro de entrevista continuará falando português, a despeito da } \\
\text { insistência do biógrafo para mudar de língua. } \\
\text { 3.3. O parceiro de entrevista falará de maneira menos sintética a respeito de } \\
\text { sua vida e de sua família. Aprofundará sua história. }\end{array}$ \\
\hline 4 & $\begin{array}{c}1 / 14-34 \\
(20)\end{array}$ & $\begin{array}{c}\text { Nome } \\
1\end{array}$ & Relato & $\begin{array}{l}\text { Terremoto, destruição, quem tinha possibilidade de viajar, viajou - decidiu } \\
\text { viajar sete meses após o terremoto; foi para o Equador porque é o país mais } \\
\text { aberto (tinha tio e primo lá); começou a sofrer (língua, racismo); três meses } \\
\text { depois estava adaptado e decidiu começar a trazer a família para morar com } \\
\text { ele no Equador. } \\
\frac{\text { Tema: terremoto / Campo temático: sofrimento associado à tragédia e }}{\text { deslocamento }} \\
\text { 4.1. Menciona o terremoto para justificar a saída do Haiti no início da } \\
\text { entrevista. } \\
\text { 4.1.1. O terremoto será a motivação principal para a saída do Haiti. } \\
\text { 4.1.2. O terremoto foi utilizado apenas para facilitar a argumentação (fazer-se } \\
\text { compreender pelo biógrafo). } \\
\text { 4.1.2.1. Outros motivos para a saída do Haiti aparecerão na narrativa. } \\
\text { 4.2. Menciona sofrimento no início da entrevista. } \\
\text { 4.2.1. Toda sua história estará permeada por alusões a momentos de } \\
\text { sofrimento. }\end{array}$ \\
\hline
\end{tabular}

\footnotetext{
${ }^{22}$ Os nomes são anonimizados de acordo com critérios que consideram contextos de origem, como nomes de origem religiosa ou étnica, o número de sílabas e a sílaba tônica, a possibilidade (ou não) de identificação de gênero, dentre outros. Ao contrário de outras abordagens, acreditamos na importância de manter elementos presentes durante a geração dos dados na situação de interação. Estes elementos devem ser reconhecidos e criteriosamente levados em consideração na análise da entrevista transcrita.
} 


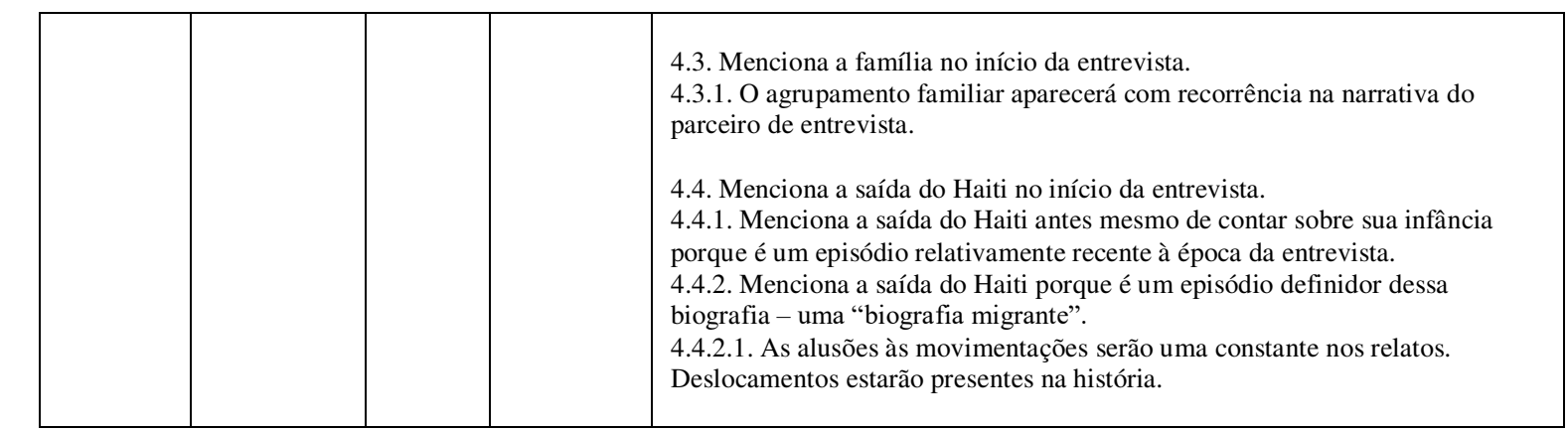

Fonte: Autores (2018).

Com base na análise de texto e do campo temático, chegamos ao interesse de apresentação do biografado: a forma (manifesta ou latente) como o parceiro de entrevista quer ser percebido quando apresenta sua biografia ao seu interlocutor na situação de entrevista (ROSENTHAL, 2017).

c) Reconstrução da vida vivenciada (erlebte Lebensgeschichte)

Esta etapa reconstrói a história vivenciada, isto é, como os eventos biográficos foram vivenciados pelo biografado (ROSENTHAL, 2014). Aqui, trabalhamos com dois níveis de análise: de um lado, têm-se as hipóteses para a vida vivenciada (passado) e, do outro, os trechos narrados (presente) a respeito do mesmo evento biográfico. O propósito da primeira é reconstruir o sentido biográfico das experiências no momento em que aconteceram e aprofundar a reconstrução da sequência cronológica e o da segunda é reconstruir os significados das experiências no presente e a ordem temporal da história no momento da entrevista: "a história de vida narrada e vivenciada sempre estão juntas, elas estão relacionadas dialeticamente e produzem uma à outra" (ROSENTHAL, 1993, p. 60, tradução dos autores). Por isso, o pesquisador deve reconstruir os dois níveis, independentemente de o objetivo da pesquisa estar relacionado a um ou outro nível específico (ROSENTHAL, 1993).

No quadro abaixo, os dados biográficos presentes na cronologia da primeira fase são contrastados com trechos da entrevista transcrita contendo as interpretações do biografado sobre o mesmo evento. Para reconstituir o passado do biografado, usamos seu interesse de apresentação e sua situação de vida no presente, o que contribui para o pesquisador reconstruir a posição de onde o parceiro de entrevista narrou sua vida no momento da entrevista (ROSENTHAL, 2014). 
Quadro 4 - Contraste entre dados biográficos e trechos da entrevista.

\begin{tabular}{|c|c|}
\hline \multicolumn{2}{|c|}{ CONTRASTE ENTRE DADO BIOGRÁFICO E TRECHOS DA ENTREVISTA } \\
\hline Hipóteses para vida vivenciada & Trechos da narrativa de vida \\
\hline $\begin{array}{c}\text { 1. VIII/1988 - Nasce em uma região rural no interior do Haiti (próxim } \\
\text { subsistência. }\end{array}$ & \\
\hline $\begin{array}{l}\text { 1.1. A família compensa dificuldades econômicas criando forte vínculo com a } \\
\text { comunidade. } \\
\text { 1.1.1. Os pais do biografado sentem-se amparados pela comunidade da região. } \\
\text { 1.1.1.1. Ele sente orgulho de suas origens. } \\
\text { 1.1.1.1.1. Ele vai crescer em um ambiente com forte sentimento comunitário e isso se } \\
\text { refletirá em escolhas relacionadas à vontade de retribuir e prestar auxílio. } \\
\text { 1.2. A família não compensa dificuldades econômicas criando vínculo com a } \\
\text { comunidade. } \\
\text { 1.2.1. Ele e sua família saem da região em busca de condições de vida mais favoráveis. } \\
\text { 1.2.2. Ele e sua família permanecem na região, mas nutrem um sentimento de } \\
\text { desamparo e descaso, que se reflete no trato violento dos pais com ele e seus irmãos. } \\
\text { 1.2.2.1. Ele cresce com dificuldades para estabelecer relações interpessoais. } \\
\text { 1.2.2.2. Ele encontra no abandono da família uma alternativa ao cotidiano violento. } \\
\text { 1.2.2.3. Ele faz escolhas que indicam a reprodução da violência familiar. } \\
\text { 1.2.3. Os pais não se sentem amparados pela comunidade na região. } \\
\text { 1.2.3.1. Ele cresce em um ambiente voltado mais para sua família do que para a } \\
\text { comunidade e isso se refletirá em suas escolhas futuras, que poderão estar relacionadas a } \\
\text { uma vontade de se distanciar da região. } \\
\text { 1.2.3.1.1. Ele tem vergonha de sua região. } \\
\text { 1.3. A gravidez foi planejada. }\end{array}$ & $\begin{array}{l}\text { A. eu nasci no interior e lá o que eu } \\
\text { fazia é de ajudar os meus pais né que } \\
\text { eles tiveram o que é fazenda né } \\
\text { ajudando a cuidar os animais e tanto } \\
\text { cultivar a terra com eles eu fui criado } \\
\text { assim bem puxado de uma forma } \\
\text { puxada duro né e e:: para mim } \\
\text { sofrimento nunca é puxado porque eu já } \\
\text { vivi a vida né bem sufrida né aí=né uma } \\
\text { vez eu fiquei pensando né bá vou passar } \\
\text { a minha vida assim na fazenda ahn não } \\
\text { tem jeito eu diz assim vou ver o que eu } \\
\text { posso aprender para me tirar de=essa } \\
\text { situação (p. } 4 \text {, 2013). } \\
\text { A. ah meu pai=meus pais me falaram } \\
\text { que [seu nascimento] foi uma coisa e: } \\
\text { tão milagre sabe e: porque e: eles tavam } \\
\text { conhecendo dificultades e: sabe } \\
\text { econômica e: coisas assim e:: então e:: } \\
\text { depois que eu nasci eu comecei e: como } \\
\text { posso dizer e: sufrir e: de e: } \\
\text { enfermidade e: sabe de criança sabe aí } \\
\text { meus pais nunca perderam o fé né sabe } \\
\text { são crentes né são crentes são } \\
\text { evangélicos né aí eles fizeram o que } \\
\text { eles poderiam fazer para mim né e o } \\
\text { resto que eles não podiam fazer Deus } \\
\text { fez né ajudou e até que minha vida } \\
\text { sempre foi uma profecia sabe (p. } 14 \text {, } \\
\text { 2013). } \\
\text { A. e: como eu nasci e: dentro de uma } \\
\text { família evangélica né eu sempre fui e: } \\
\text { evangélico sabe [...] todo mundo tem } \\
\text { que ter uma tem que confiar em uma } \\
\text { coisa seja em Deus ou em seu trabalho } \\
\text { em sua força em seu próprio ser tendeu } \\
\text { todo mundo tem que confiar em alguma } \\
\text { coisa sabe então eu confio em Deus e eu } \\
\text { faço muitas experiências sabe (p. } 20-21 \text {, } \\
\text { 2013). }\end{array}$ \\
\hline $\begin{array}{l}\text { 1.5. A família conta com o auxílio financeiro de familiares que vivem no exterior. } \\
\text { 1.5.1. Ele cresce em um ambiente no qual pode ser estabelecida uma associação entre } \\
\text { "país estrangeiro" e melhores condições de vida. } \\
\text { 1.5.1.1. Ele pode optar por viver fora do Haiti. } \\
\text { 1.5.2. Ele cresce em um ambiente no qual pode ser estabelecida uma associação entre } \\
\text { sua família e a vida que vivenciam no interior com a falta de recursos e a pobreza. } \\
\text { 1.5.2.1. Ele desenvolve um sentimento de vergonha em relação a sua família. } \\
\text { 1.5.2.1.1. Ele se afasta de sua família e da sua região. }\end{array}$ & \\
\hline
\end{tabular}

Fonte: Autores (2018).

d) Contraste entre vida vivenciada (passado - erlebte Lebensgeschichte) e vida narrada (presente - erzählte Lebensgeschichte) e construção tipológica

O contraste entre vida vivenciada e vida narrada procura esclarecer "mecanismos de seleção de experiências para a história vivenciada, a forma como são apresentados e as diferenças entre as perspectivas atual e passada; de modo geral, fornece conhecimento a 
respeito das diferenças da temporalidade entre o narrado e o vivenciado" (ROSENTHAL, 1993, p. 66, tradução dos autores). Esta etapa utiliza informações presentes no memorando escrito para as entrevistas, os resultados da análise de campo temático (o interesse de apresentação do biografado), a reconstrução do caso (a disposição cronológica da vida do biografado agregando o nível do narrado e do vivenciado) e as considerações finais (ROSENTHAL, 2014). Esta fase corresponde à análise final do caso e apresenta uma figura geral para a reconstrução. Ela consiste na sistematização e no contraste entre as diversas fases.

Após a reconstrução dos casos, o pesquisador pode utilizar seu problema de pesquisa para estabelecer uma tipologia, cujo foco são as experiências subjetiva e social do indivíduo (Ibidem). No caso específico de um estudo sobre construção do pertencimento na vida de um migrante, parte-se dessa pergunta para sugerir a generalização teórica para casos similares abrangidos pelo tipo constituído com base na reconstrução do caso (Ibidem). De acordo com Rosenthal (2014, p. 91), "um tipo abrange casos semelhantes, e isso independe da frequência com que esses ocorrem. No processo de determinação da tipicidade de um caso, [...] sua regularidade não tem nenhuma relevância”. Isto é, mesmo um caso que tenha uma única ocorrência pode configurar um tipo, apesar de sua frequência empírica não ser alta: "é perfeitamente possível que casos pouco frequentes de determinado tipo exerçam maior influência sobre a realidade social do que casos mais regulares, mas relativos a outro tipo" (ROSENTHAL, 2014, p. 93). Como Rosenthal (2014, p. 91) sugere, "determinante para a tipicidade de um caso são as regras que o produzem, que dão ordem à diversidade de partes", em outras palavras, as regras que estruturam o caso.

Uma vez que é impossível determinar a estrutura de um tipo baseando-se apenas na similaridade exterior de seus elementos, para estabelecer uma tipologia é imprescindível fazer uma análise histórico-reconstrutiva que indique como foi possível que algo se tornasse o que é em sua manifestação no presente (DAUSIEN, 1999). Formas semelhantes são possíveis mesmo que todas suas partes componentes sejam diferentes; do mesmo modo, as formas podem ser substancialmente diferentes, mas apresentar grande similaridade entre suas partes (ROSENTHAL, 2014).

Nesse caso, não se fala em termos de estabelecer uma tipologia descritiva do fenômeno ou detalhar especificidades típicas ao caso, mas "no contexto da comparação entre dois casos, apenas na conclusão de ambas as reconstruções é possível dizer se se tratam de dois representantes diferentes de um mesmo tipo ou de dois tipos totalmente diversos" (ROSENTHAL, 2014, p. 92). O objetivo é construir tipos que indiquem as regras que permitem explicá-los e que não se limitem a uma descrição de características observáveis 
superficialmente por uma lógica classificatória, o que é feito, geralmente, em estudos de caso (ROSENTHAL, 2014).

\section{Dois estudos de reconstrução biográfica de casos com base em entrevistas narrativas biográficas}

Gostaríamos de apresentar como exemplos da aplicação do método de entrevistas narrativas biográficas um estudo realizado na Alemanha (2004-2005) com jovens no mercado de trabalho e um estudo realizado no Brasil (2012-2014) sobre mulheres como autoras de violência. ${ }^{23}$ Ambos os estudos se caracterizam principalmente por permitirem análises mais densas e a descoberta de dinâmicas sociais ainda pouco apreendidas em seus campos ao invés de descrever casos encontrados durante o trabalho de campo.

No estudo realizado na Alemanha (ROSENTHAL et al., 2006) foram investigados os efeitos de uma medida socioeducativa sobre a trajetória profissional de jovens no ano de 2000. Tratava-se de jovens que passavam por processos de evasão escolar, com baixa adesão a cursos de aprendizagem técnica, enfrentando dificuldades para ingressar no mercado de trabalho. Ao final da medida, uma parte dos jovens teve alguma inclusão escolar ou de trabalho, outra parte não teve nenhuma. O estudo tinha dois objetivos: entender o efeito que o projeto socioeducativo teve sobre os jovens e sugerir, a partir da experiência com as entrevistas, instrumentos eficazes para a condução de conversas no acompanhamento social. Foram feitas entrevistas narrativas biográficas com 28 jovens (de 16 a 27 anos), que participaram durante seis meses da medida socioeducativa e obtiveram alguma ou nenhuma inclusão.

A análise das entrevistas possibilitou a reconstrução de mais de sete casos, que deram origem a seis tipos diferentes de efeitos de curto e de longo prazo da medida socioeducativa. Os seguintes tipos foram encontrados: a) permanência dos padrões de comportamento prejudiciais (como baixa autoestima) e sucesso escolar; b) consolidação dos padrões de comportamento prejudiciais e sucesso escolar; c) primeiras mudanças dos padrões de comportamento prejudiciais e destrutivos e sucesso escolar; d) permanência dos padrões de comportamento prejudiciais sem sucesso escolar; e) consolidação dos padrões de

\footnotetext{
${ }^{23}$ O primeiro estudo foi realizado na Alemanha por Gabriele Rosenthal e colaboradores (ROSENTHAL et al., 2006). O segundo, foi realizado por Hermílio Santos no Brasil (SANTOS, 2016).
} 
comportamento prejudiciais sem sucesso escolar; f) primeiras mudanças dos padrões de comportamento prejudiciais e destrutivos sem sucesso escolar. ${ }^{24}$

Um dos mais importantes resultados do estudo foi identificar que, diferentemente do que se pensava, após quatro a cinco anos do fim da medida, mesmo os jovens que haviam tido alguma inclusão não obtiveram mudanças efetivas nos seus modos de ação, mantendo comportamentos destrutivos e baixa autonomia (em um estudo descritivo, os casos provavelmente seriam classificados todos como casos de inclusão, mas não reconstruiriam a gênese e a manutenção dos comportamentos destrutivos e da baixa autonomia). Tais resultados demonstram como o método permite evidenciar relações causais que vão além das unilineares, já que a inclusão não significou uma mudança de longo prazo, de modo que a política não atingiu o seu objetivo (RINALDI, 2016).

As entrevistas possibilitaram, por fim, a autorreflexão crítica nos jovens sobre sua biografia, história familiar e situação atual, incentivando a auto-compreensão (Selbstverstehen). A reconstrução dos casos evidenciou as limitações dos assistentes sociais no processo de compreensão do outro (Fremdverstehen), uma vez que os métodos de acompanhamento convencionais demonstraram restringir seu entendimento sobre as dificuldades escolares e de ocupação dos jovens ao presente, sem realizar conexões mais substanciais com o seu passado. Estes métodos convencionais possuem, em grande parte, um efeito destrutivo, levando à construção de culpa nos jovens e também nos próprios assistentes, pois ambos não atingem seus objetivos socialmente estipulados nessa interação: um de incluir-se no mercado de trabalho e o outro de contribuir para a inclusão.

No estudo realizado no Brasil, foi abordado o envolvimento de mulheres em crimes e ações violentas. As entrevistas foram geradas com mulheres autoras de violência, podendo ser identificadas uma série de experiências distintas dessas mulheres com práticas violentas. $\mathrm{O}$ estudo demonstrou que os papéis assumidos por mulheres em práticas violentas são bastante diversos, distanciando-se da literatura vigente, que compreende a participação de mulheres em ações violentas como secundária e, em geral, atrelada à figura masculina.

De fato, apresentaram-se casos nos quais observou-se algo semelhante ao que se denominaria o "domínio masculino". Esse foi o caso da entrevista com Fabíola, na qual as análises demonstraram como a entrevistada fazia uso da relação com seu namorado para superar dificuldades familiares e assegurar a vida financeira. Seu envolvimento em crimes com o namorado não demonstrava subordinação à figura masculina, mas um cálculo de

\footnotetext{
${ }^{24}$ Para mais, ver Rosenthal et al. (2006).
} 
vantagens, mesmo que isso significasse assumir riscos. O estudo sobre mulheres como autoras de violência foi feito após a finalização de um estudo quantitativo realizado entre os anos de 2012 e 2014 em comunidades no Rio de Janeiro, Recife e São Paulo. Ambos os estudos exemplificam a possibilidade de combinar pesquisas que usam os métodos de entrevista narrativa biográfica e de reconstrução biográfica de caso com pesquisas quantitativas em contextos de pesquisas que procuram compreender e explicar como as pessoas vivenciam fenômenos como o da violência e da inclusão no mercado de trabalho a partir de seu cotidiano e de seus sistemas de relevância.

\section{Considerações Finais}

O artigo apresentou os métodos de entrevista narrativa biográfica e de reconstrução biográfica de caso da socióloga alemã Gabriele Rosenthal, exemplificando suas etapas de geração e análise dos dados e incluiu reflexões metodológicas a partir de nossas experiências (CÉ SANGALLI, 2015; RINALDI, 2018; CÉ SANGALLI, 2018). Os métodos colocam em prática os fundamentos teóricos e metodológicos da pesquisa social interpretativa, como os princípios da comunicação, da abertura e da sequencialidade. Um resultado da opção por métodos com tal nível de abertura na geração e na análise dos dados permite, pela produção de narrativas e pela reconstrução dos casos, compreender e explicar a ação social e a gênese das experiências dos sujeitos em constituição mútua com a sociedade e a partir de suas vivências cotidianas. Esse posicionamento em relação a uma sociologia que leva em consideração dinâmicas individuais e sociais com base em uma perspectiva processual contribui para o estabelecimento de uma sociologia histórica, avançando em relação à parcela significativa da produção científica qualitativa. Atualmente, grande parte destas pesquisas mantêm seu foco na descrição densa de fenômenos e práticas ou em micro-etnografias do cotidiano, deixando em segundo plano a necessidade de compreender e explicar os processos de formação, desenvolvimento e transformação dos fenômenos. ${ }^{25}$

Para tanto, mostramos a necessidade de reconstruir tanto o percurso biográfico passado quanto as construções de sentido no presente. Na reconstrução, é possível evidenciar a gênese do fenômeno social, seu surgimento, conservação e modificação no decorrer do processo biográfico (ROSENTHAL, 2014). Isto se torna possível quando investigamos o que os indivíduos vivenciaram, qual sentido atribuíram a suas ações no passado e qual atribuem

\footnotetext{
${ }^{25}$ Para mais sobre a necessidade e a importância de a sociologia considerar as perspectivas históricas e processuais em suas análises, ver Rosenthal (2012; 2016b) e Elias (1987).
} 
no presente a partir do contexto de sua vida atual, na qual inserem suas vivências (Ibidem). Schütz (2004) já discutira, a partir de Husserl, sobre o modo como os sujeitos constituem suas experiências e como elas passam a fazer parte do seu repertório na tomada de decisão no curso da ação. Ao agirmos, isto é, ao nos inclinarmos ao futuro, recorremos a experiências realizadas ao longo de nossa biografia. Nesse sentido, uma abordagem biográfica permite analisar os níveis sincrônico e diacrônico da construção das biografias, bem como ter uma noção dos padrões que poderão se repetir no futuro (ROSENTHAL, 2014; SANTOS 2017).

Embora o interesse por pesquisas e métodos biográficos nas ciências sociais brasileiras tenha sido tímido até a virada do século XXI, percebemos um interesse crescente pelo uso de estudos biográficos e narrativos na sociologia brasileira em anos recentes (SANTOS; OLIVEIRA; SUSIN, 2014; DA CUNHA; ALHEIT, 2018). Em 2017, o Grupo de Trabalho Biografia e Sociedade (GT 10) reuniu-se pela primeira vez no $18^{\circ}$ Congresso Brasileiro de Sociologia em Brasília, no qual foram apresentados em torno de 30 trabalhos com esta temática, além da apresentação de estudos com base biográfica e da discussão sobre memória e narrativa em outros grupos de trabalho. Em julho de 2018, o primeiro representante nãoeuropeu, o brasileiro Hermílio Santos, foi eleito presidente do comitê de pesquisa "Biografia e Sociedade" (RC 38) da Associação Internacional de Sociologia (ISA). Este interesse atesta a relevância sociológica e a contemporaneidade dos métodos e abordagens da pesquisa biográfica e narrativa, bem como o reconhecimento internacional que os estudos brasileiros têm ganhado. Dessa maneira, acreditamos que a pesquisa social interpretativa alemã e os métodos aqui expostos contribuem de forma significativa para discussões na sociologia brasileira, seja pela possibilidade da descoberta do novo e do desconhecido, como evidenciado nos exemplos de estudos na Alemanha e no Brasil, seja pela consciência empírica que exige dos pesquisadores que os utilizam. 


\section{Referências}

BECKER, Howard. Métodos de Pesquisa Social em Ciências Sociais. São Paulo: Editora Hucitec, 1993.

BERGER, Peter; LUCKMANN, Thomas. A Construção social da Realidade. Petrópolis: Vozes, 1985.

BERTAUX, Daniel. L'enquête et ses méthodes. Le récit de vie. Paris: Armand Colin, 2010. ; KOHLI, Martin. The Life Story Approach: A Continental View. In: Annual Review of Sociology, v. 10, 1984. p. 215-237.

BOGNER, Artur; ROSENTHAL, Gabriele. Biographies - Discourses - Figurations:

Methodological considerations from the perspectives of social constructivism and figurational sociology. In: ROSENTHAL, G.; BOGNER, A. (Ed.). Biographies in the Global South. Frankfurt a. M.: Campus, 2017. p. 15-49.

CÉ SANGALLI, Lucas. O desaparecimento de Alain: movimento e pertencimento na vida de um migrante. 2015. 93f. Dissertação (Mestrado em Ciências Sociais) - Programa de PósGraduação em Ciências Sociais, Pontifícia Universidade Católica do Rio Grande do Sul, Porto Alegre, 2015.

. A construção social do espaço para si: pertencimento na biografia de um migrante.

In: Revista Mosaico (CPDOC/FGV), Rio de Janeiro, v. 9, n. 14, 2018. p. 338-358.

DA CUNHA, Jorge Luiz; ALHEIT, Peter. Biographieforschung in Brasilien. In: LUTZ, H.; SCHIEBEL, M.; TUIDER, E. Handbuch Biographieforschung. Frankfurt: Springer VS, 2018. p. 789-797.

DAUSIEN, Bettina. "Geschlechtsspezifische Sozialisation" - Konstruktiv(istisch)e Ideen zur Karriere und Kritik eines Konzepts. In: DAUSIEN, B. et al (Orgs.). Erkenntnisprojekt Geschlecht - Feministische Perspektiven verwandeln Wissenschaft. Opladen: Leske + Budrich, 1999. p. 217-246.

ELIAS, Norbert. The Retreat of Sociologists into the Present. In: Theory, Culture \& Society, v. 4 , n. 2-3, 1987. p. 223-247.

A sociedade dos indivíduos. Rio de Janeiro: Zahar, 1994.

FANN, Kuni. Peirce's Theory of Abduction. The Hague: Martinus Nijhoff, 1970.

FREUND, Julian. Sociologia de Max Weber. Rio de Janeiro: Editora Forense Universitária, 2003.

GLASER, Barney; STRAUSS, Anselm. The Discovery of Grounded Theory: Strategies for qualitative research. New Brunswick: Aldine Transaction, 1967.

GOFFMAN, Ervin. Frame analysis. An essay on the organization of experience. York: The Maple Press, 1986. 
HOFFMANN-RIEM, Christa. Die Sozialforschung einer interpretativen Soziologie. Der datengewinn. In: Kölner Zeitschrift für Soziologie und Sozialpsychologie, a. 2, n. 32, 1980. p. 339-372.

HOPF, Christel. Die Pseudo-Exploration - Überlegungen zur Technik qualitativer Interviews in der Sozialforschung. In: Zeitschrift für Soziologie, Jg. 7, Heft 2, 1978. p. 97-115.

KLEEMANN, Frank; KRÄHNKE, Uwe; MATUSCHEK, Ingo. Grundlagen interpretativer Sozialforschung. In: KLEEMANN, F. et al. Interpretative Sozialforschung: Eine praxisorientierte Einführung. Wiesbaden: VS Verlag für Sozialwissenschaftler, 2009. p. 1334.

KNOBLAUCH, Hubert. Wissenssoziologie. Konstanz: UVK, 2005.

KÖTTIG, Michaela; VÖLTER, Bettina. Isso, sim, é ser sociólogo! Uma entrevista narrativa com Fritz Schütze sobre a história de sua obra na sociologia. In: Civitas, Porto Alegre, v. 14, n. 2, 2014. p. 204-226.

LAHIRE, Bernard. Patrimônios individuais de disposições - Para uma sociologia à escala individual. In: Sociologia, Problemas e Práticas, n. 49, 2005. p. 11-42.

Sociological biography and socialisation process: a dispositionalist-contextualist conception. In: Contemporary Social Science, 2017. Disponível em https://doi.org/10.1080/21582041.2017.1399213. Acessado em 17/06/2018.

OEVERMANN, Ulrich; ALLERT, Tilman; KONAU, Elisabeth; KRAMBECK, Jürgen. Die Methodologie einer objektiven Hermeneutik und ihre allgemeine forschungslogische Bedeutung in den Sozialwissenschaften. In: SOEFFNER, H.-G. (Ed.). Interpretative Verfahren in den Sozial- und Textwissenschaften. Stuttgart: Metzler, 1979. p. 352-434.

RADENBACH, Niklas; ROSENTHAL, Gabriele. Das Vergangene ist auch Gegenwart, das Gesellschaftliche ist auch individuell: zur Notwendigkeit der Analyse biographischer und historischer Rahmendaten. In: Sozialersinn, v. 1, n. 13, 2012. p. 3-37.

RINALDI, Débora. Trabalho e geração de renda nas classes populares a exemplo do grupo de catadores de resíduos. In: Contraponto, Porto Alegre, v. 3, n. 2, 2016. p. 23-39.

A interpretação da catação pelos catadores: um estudo biográfico. 2018. $169 f$ f. Dissertação (Mestrado em Ciências Sociais) - Programa de Pós-Graduação em Ciências Sociais, Pontifícia Universidade Católica do Rio Grande do Sul, Porto Alegre, 2018.

ROSENTHAL, Gabriele. Reconstruction of life stories: principles of selection in generating stories for narrative biographical interviews. In: The narrative study of lives 1, v. 1, n. 1, 1993. p. 59-91.

\section{3.}

. The healing effects of storytelling. In: Qualitative Inquiry, v. 9, n. 6, 2003. p. 915- 
A plea for a more interpretive, more empirical and more historical sociology. In:

KALEKIN-FISHMAN, D.; DENIS, A. (Eds.). The shape of sociology in the 21st Century: tradition and renewal. Thousand Oaks: Sage Publications, 2012. p. 202-217.

ROSENTHAL, Gabriele. Pesquisa social interpretativa: uma introdução. Porto Alegre: Edipucrs, 2014.

The social construction of individual and collective memory. In: SEBALD, G.; WAGLE, J. (Eds.). Theorizing Social Memories: Concepts, Temporality, Functions. London: Routledge, 2016a. p. 2-55.

Die Erforschung kollektiver und individueller Dynamik - Zu einer historisch und prozess-soziologisch orientierten interpretativen Sozialforschung. In: Forum Qualitative Sozialforschung, v.7, n. 2, 2016b. Art. 13.

2017.

História de vida vivenciada e história de vida narrada. Porto Alegre: Edipucrs,

; KÖTTIG, Michaela; WITTE, Nicole; BLEZINGER, Anne. Biographisch-narrative Gespräche mit Jugendlichen. Chancen für das Selbst- und Fremdverstehen. Oplanden: Barbara Budrich, 2006.

; WORM, Arne. Geschichtswissenschaft/Oral History und Biographieforschung. In: LUTZ, H. et al (Hrsg.). Handbuch Biographieforschung, 2018. p. 151-161.

SANTOS GONÇALVES, Maria do Carmo dos; CÉ SANGALLI, Lucas. A abordagem biográfica das migrações transnacionais: os casos haitiano e senegalês no Brasil. In: Revista Brasileira de Pesquisa (Auto)Biográfica, Salvador, v. 3, n. 7, 2018. p. 91-108.

SANTOS, Hermílio. Mulheres como autoras de violência: evidências e agenda de pesquisa. In: Civitas, Porto Alegre, v. 16, n. 1, 2016. p. 42-58.

A Sociologia de Alfred Schütz. In: SELL, C.; MARTINS, C. (Org.). Teoria sociológica contemporânea: autores e perspectivas. São Paulo: Annablume, 2017. p. 195213.

; OLIVEIRA, Patrícia; SUSIN, Priscila. Narrativas e pesquisa biográfica na sociologia brasileira: revisão e perspectivas. In: Civitas, v. 14, n. 2, 2014. p. 359-382.

; VÖLTER, Bettina; WELLER, Wivian. Narrativas - teorias e métodos

(Apresentação). In: Civitas, v. 14, 2014. p. 199-203.

SCHÜTZ, Alfred. Der sinnhafte Aufbau der sozialen Welt: Eine Einleitung in die verstehende Soziologie. Konstanz: UVK, 2004.

SCHÜTZE, Fritz. Biographieforschung und narratives Interview. In: Neue Praxis, v. 13, n. 3, 1983. p. 283-293.

Pesquisa biográfica e entrevista narrativa. In: WELLER, W.; PFAFF, N. (Org.).

Metodologia da pesquisa qualitativa na educação. Petrópolis: Vozes, 2010. p. 210-222. 
VELHO, Gilberto. Goffman, mal-entendidos e riscos interacionais. In: Revista Brasileira de Ciências Sociais, v. 23, n. 68, 2008. p. 145-198.

Individualismo e cultura. Rio de Janeiro: Zahar, 2012a.

\section{2.}

Homenagem a Gilberto Velho [Memorial]. In: MANA, v. 18, n. 1, 2012b. p. 173-

ZARADER, Marlène. Lire Être et Temps de Heidegger. Paris: VRIN, 2012.

Recebido em 06-08-2017;

Revisado em 17-04-2018;

Publicação em 15-12-2018. 